\title{
Human liver chimeric mice provide a model for hepatitis $B$ and $C$ virus infection and treatment
}

\author{
Karl-Dimiter Bissig, ${ }^{1}$ Stefan F. Wieland, ${ }^{2}$ Phu Tran, ${ }^{1}$ Masanori Isogawa, ${ }^{2}$ Tam T. Le, ${ }^{1}$ \\ Francis V. Chisari, ${ }^{2}$ and Inder M. Verma ${ }^{1}$
}

\begin{abstract}
${ }^{1}$ The Salk Institute for Biological Studies, Laboratory of Genetics, La Jolla, California, USA. ${ }^{2}$ The Scripps Research Institute,
\end{abstract} Department of Immunology and Microbial Science, La Jolla, California, USA.

\begin{abstract}
A paucity of versatile small animal models of hepatitis B virus (HBV) and hepatitis $\mathrm{C}$ virus (HCV) infection has been an impediment to both furthering understanding of virus biology and testing antiviral therapies. We recently described a regulatable system for repopulating the liver of immunodeficient mice (specifically mice lacking fumaryl acetoacetate hydrolase [Fah], recombination activating gene 2 [Rag2], and the $\gamma$-chain of the receptor for IL-2 [Il-2r $\gamma]$ ) with human hepatocytes. Here we have shown that a high transplantation dose $\left(3 \times 10^{6}\right.$ to $5 \times 10^{6}$ human hepatocytes/mouse) generates a higher rate of liver chimerism than was previously obtained in these mice, up to $95 \%$ human hepatocyte chimerism. Mice with a high level of human liver chimerism propagated both $\mathrm{HBV}$ and $\mathrm{HCV}$, and the $\mathrm{HCV}$-infected mice were responsive to antiviral treatment. This human liver chimeric mouse model will expand the experimental possibilities for studying HBV and HCV infection, and possibly other human hepatotropic pathogens, and prove useful for antiviral drug testing.
\end{abstract}

\section{Introduction}

HBV is the prototype for the Hepadnaviridae family of hepatotropic, partially double-stranded DNA viruses (1), while HCV is a single-stranded RNA virus in the Flaviviridae family (2). Although very different at the molecular level, $\mathrm{HBV}$ and $\mathrm{HCV}$ share many similarities as pathogens; their host range is restricted to humans and chimpanzees, and their primary site of infection is the liver. Both infections can be acute or chronic, the latter leading to cirrhosis and eventually liver cancer (3). Together, HCV and HBV chronically infect more than 500 million people worldwide and account for about two-thirds of all hepatocellular carcinoma, the third most common cause of cancer-related death (4).

When HBV enters hepatocytes, the partially double-stranded DNA of the virus is released, transferred to the nucleus, and converted into covalently closed circular DNA (cccDNA) (1). The cccDNA in turn serves as a template for transcription of several viral mRNAs by the host RNA polymerase II machinery. One of them, the pregenomic RNA (pgRNA), encodes the viral capsid protein $(\mathrm{HBcAg})$ and the reverse transcriptase, which synthesizes viral DNA intermediates within the viral capsid. In contrast, the HCV life cycle is entirely cytoplasmic. The single-stranded RNA serves as a template for replication and translation. The latter results in a single polyprotein precursor, which is eventually cleaved into structural (C, E1, E2, p7) and nonstructural proteins (NS2-5) (2).

Our knowledge of the life cycles of both viruses and the development of the corresponding antiviral drugs are hampered by the lack of easily manipulatable small animal models for both pathogens. Although chimpanzees are susceptible to both infections (5-7), their usage is limited for ethical and practical reasons (5). Other hepadnaviruses that infect ducks (8), woodchucks (9), and ground squirrels (10) have been widely used as surrogates to study HBV biology (1), but they are outbred and suffer from the limitations

Conflict of interest: The authors have declared that no conflict of interest exists. Citation for this article: J Clin Invest. 2010;120(3):924-930. doi:10.1172/JCI40094. attendant to genetic heterogeneity, restricted reagents, and our understanding of the immunobiology of the hosts. Hydrodynamic transfection of the mouse liver by the HBV genome has also been used to study HBV immunobiology (11), but it does not support viral infection. Therefore, a robust and reproducible small animal model of bona fide HBV infection would be very valuable.

The immunodeficient uPA mouse (12) permits repopulation of the liver with human hepatocytes that can be infected with HBV (13) or HCV (14). The uPA mouse model, however, has certain limitations that include excessive mortality, low breeding efficiency, transgene reversion, and overall colony management. Grompe and colleagues as well as our group have recently described a new model, the $\mathrm{Fah}^{-1-} \mathrm{Rag}^{-/-} \mathrm{Il} 2 \mathrm{rg}^{-/-}$mouse $(15,16)$, that has solved many of these problems. We have shown that this immunodeficient but otherwise healthy mouse strain can be readily and reproducibly engrafted with human hepatocytes, irrespective of the age of the mouse (16). In this mouse strain, the selection pressure for transplanted hepatocytes is accentuated due to absence of the enzyme fumaryl acetoacetate hydrolase (FAH), which leads to an accumulation of toxic tyrosine catabolites within mouse hepatocytes (17). This genetically determined toxicity is preventable by oral administration of 2-(2-nitro-4-trifluoro-methylbenzoyl)-1,3-cyclohexanedione (NTBC), which blocks hydroxyphenylpyruvate dioxygenase activity upstream of FAH and therefore prevents the accumulation of hepatotoxic metabolites.

Here we show that the $\mathrm{Fab}^{-/-} \mathrm{Rag}^{-/-} \mathrm{Il} 2 \mathrm{rg}^{-/-}$mouse liver can be very efficiently repopulated by human hepatocytes after withdrawal of NTBC and infected by HBV and HCV. In addition, we demonstrate the suitability of this model for antiviral drug testing.

\section{Results}

Robust repopulation with human hepatocytes. To undertake infections with hepatotropic human viruses, we first devised novel strategies to increase the extent of human hepatocyte reconstitution in $\mathrm{Fab}^{-/-} \mathrm{Rag2}^{-/-} \mathrm{Il} 2 \mathrm{rg}^{-/}$mice. This involved primarily increasing 
Table 1

Repopulation rates of 50 human liver chimeric mice

\begin{tabular}{lcc} 
Mice $(\boldsymbol{n})$ & $\begin{array}{c}\text { Mean HSA level } \\
(\mathbf{m g} / \mathbf{m l})\end{array}$ & $\begin{array}{c}\text { Average human liver } \\
\text { chimerism }(\%)^{\mathrm{A}}\end{array}$ \\
8 & 0.8 & 2.6 \\
4 & 3.1 & 15.8 \\
10 & 5.1 & 27.5 \\
4 & 7.6 & 42.1 \\
5 & 8.6 & 48.4 \\
10 & 10.7 & 60.6 \\
4 & 12.7 & 72.6 \\
3 & 14.9 & 85.3 \\
2 & 16.9 & 96.9 \\
Total, 50 & Average, 7.6 & Average, 42.4 \\
\hline
\end{tabular}

AAverage human liver chimerism is given as function of the correlation between human serum albumin (HSA) and FAH immunostaining (Figure $1 \mathrm{~F})$ and was confirmed $( \pm 10 \%)$ by anti-FAH immunostaining in each group.

the number of transplanted human hepatocytes (see Methods for details). Briefly, we transplanted 50 animals with $3 \times 10^{6}$ to $5 \times 10^{6}$ human hepatocytes from 12 different donors (4-67 years; Supplemental Table 1; supplemental material available online with this article; doi:10.1172/JCI40094DS1) and with no pretreatment other than NTBC. Table 1 shows that in 50 reconstituted mice, an average human albumin level of $7.6 \mathrm{mg} / \mathrm{ml}$ was detected in the mouse serum. Based on quantitative morphometry of FAH-positive, human hepatocytes in the mouse liver, this corresponds to a chimerism of $42 \%$ (see also Figure 1F). These levels were about 10-100 times higher than previously reported (16). Figure 1, A-D, shows a highly repopulated mouse with near complete humanization of the mouse liver as evidenced by immunostaining for FAH and human-specific cytokeratin 18 antibodies. It thus appears that

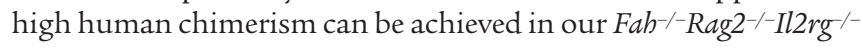
mouse strain by simply transplanting more human hepatocytes.

Since human albumin is a convenient, noninvasive marker for human hepatocyte repopulation, we analyzed the correlation between human albumin levels in the murine serum and immunostaining for $\mathrm{FAH}$. Figure $1 \mathrm{~F}$ shows a good correlation by regression analysis $\left(r^{2}=0.88\right)$. Therefore, only a few microliters of murine blood are needed for estimating human hepatocyte repopulation.

$H B V$ infection in human liver cbimeric mice. We inoculated 4 highly repopulated mice with HBV (see Methods). After 6 weeks, maximal serum titers of up to $8.15 \times 10^{8}$ genome equivalents $(\mathrm{GE}) / \mathrm{ml}$ were observed. Analysis of liver tissue at 2 and 7 weeks after inoculation confirmed intrahepatic propagation and revealed a commensurate increase in HBV cccDNA (from 1.2 to 98 copies/ng human liver
A

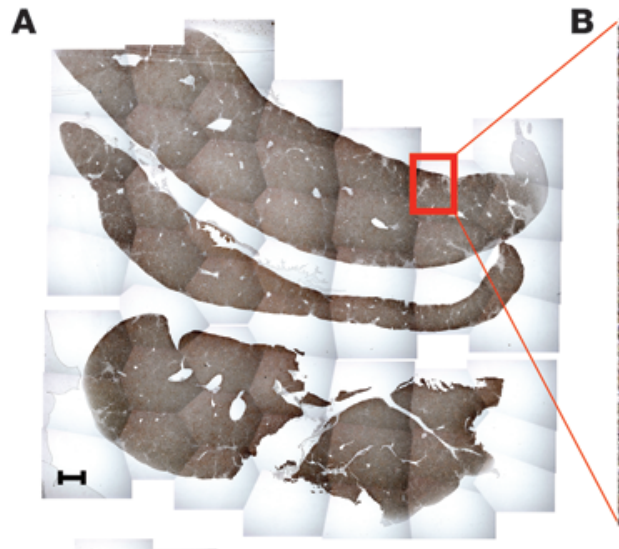

c

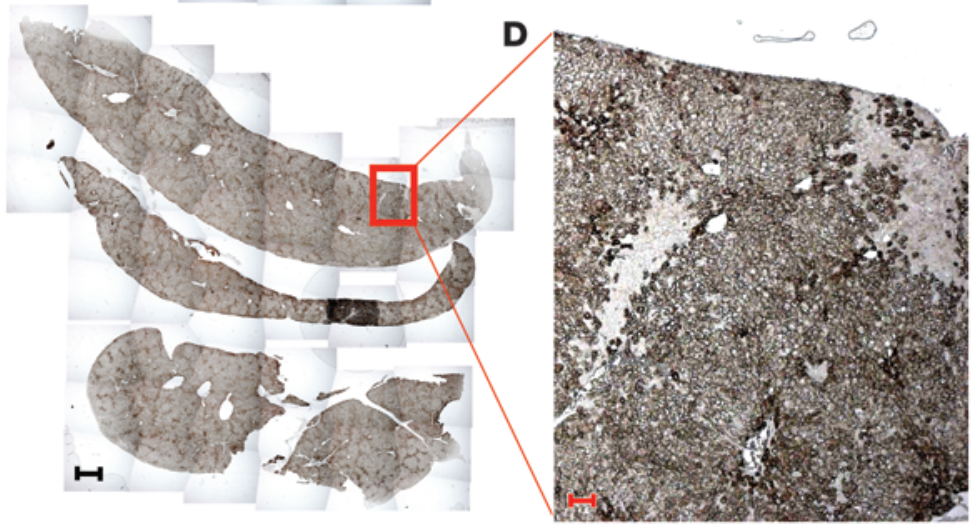

E

$\mathbf{F}$
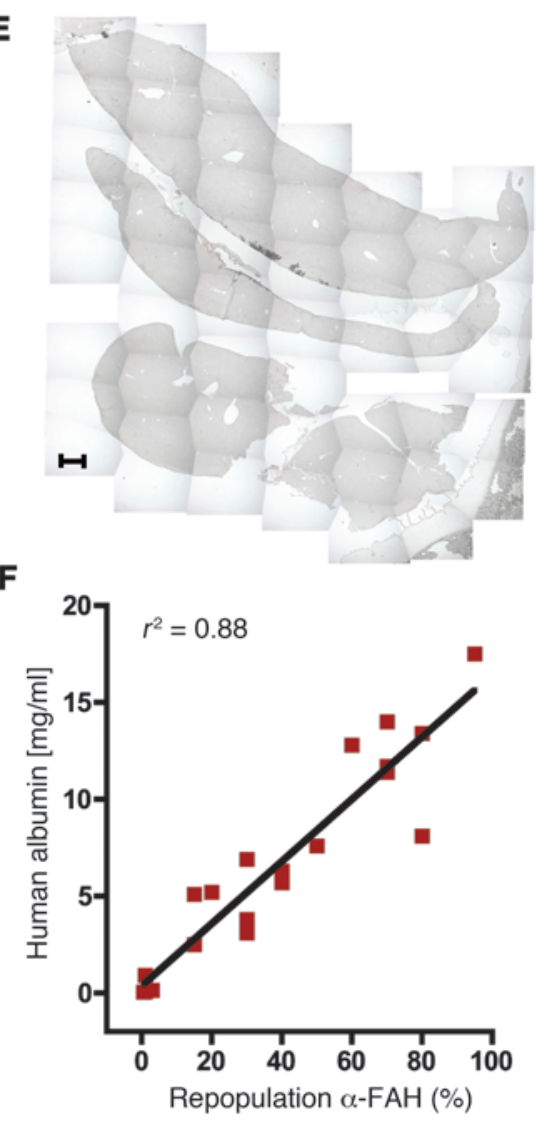

Figure 1

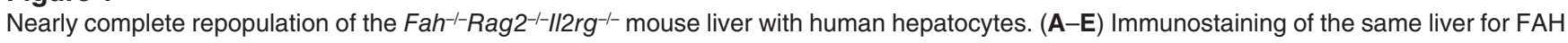
(A and B), human-specific cytokeratin-18 (C and D), and no primary antibody (control, E). (B and D) Higher-magnification views of the boxed areas in $\mathbf{A}$ and $\mathbf{C}$, respectively. Scale bars: $1 \mathrm{~mm}(\mathbf{A}, \mathbf{C}$, and $\mathbf{E}), 50 \mu \mathrm{m}(\mathbf{B}$ and $\mathbf{D})$. (F) Correlation of human albumin level in the murine serum and repopulation as assessed by morphometry of FAH immunostaining. A, C, and $\mathbf{E}$ are composite images. 
A

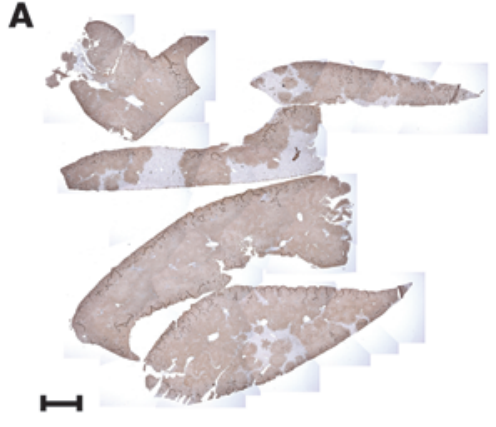

B

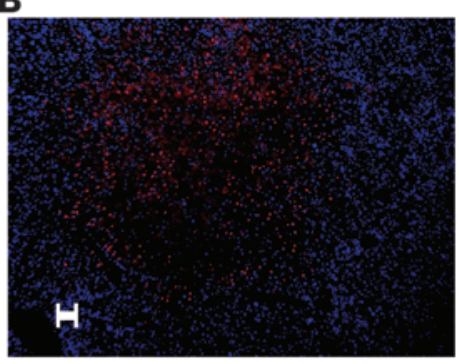

\section{Figure 2}

HBV-infected mouse with high human chimerism. (A) Immunostaining for $\mathrm{FAH}$ and counterstaining with hematoxylin shows that $80 \%$ of the liver consists of human hepatocytes. (B) Immunostaining for HBcAg (red) and counterstaining with DAPI (blue). (C and D) Fluorescent costaining for FAH (green) and HBcAg (red). The image in $\mathbf{D}$ is a higher-magnification view of the boxed area in C. B and C show the same human hepatocyte cluster. Scale bars: $1 \mathrm{~mm}$ (A), $50 \mu \mathrm{m}$ (B-D). A is a composite image.

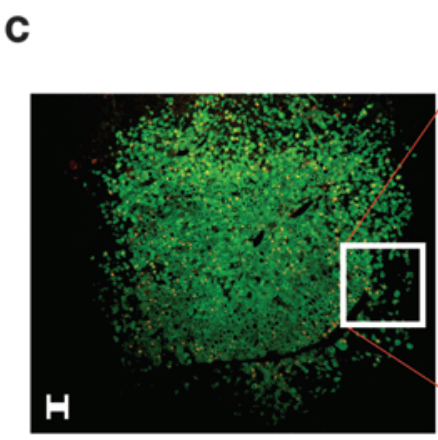

D

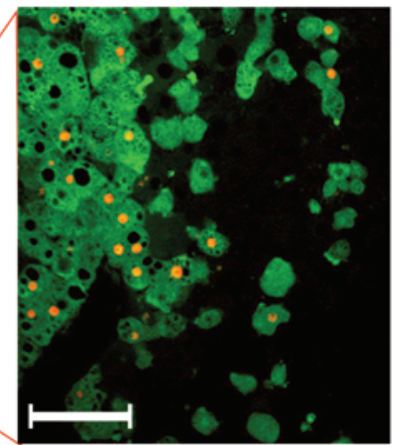

DNA), HBV RNA (from 206 to 5,550 copies/ng human liver RNA), and HBV DNA replicative intermediates (from 1,001 to 58,000 copies/ng human liver DNA). Figure 2A shows a highly repopulated chimeric mouse liver ( $~ 80 \%$ chimerism) that was inoculated with $\mathrm{HBV}$. Costaining for $\mathrm{HBcAg}$ and $\mathrm{FAH}$ revealed extensive infection of human hepatocytes (Figure 2, B-D). Within a given cluster, $50 \%-80 \%$ of human hepatocytes stained for HBcAg with the typical strong nuclear and faint cytoplasmic distribution. While mouse tissue was subject to tyrosine-related toxicity and hence cell death, we did not observe any cytopathic effect related to HBV infection in the human counterpart (Supplemental Figure 1).

Interestingly, 4 additional animals with very low human albumin levels $(0.04-0.16 \mathrm{mg} / \mathrm{ml})$ could also be infected with HBV. The presence of HBV intermediates, cccDNA, as well as HBV RNA in liver tissue confirmed viral propagation. The sparse human hepatocytes in the murine liver stained positive for $\mathrm{HBcAg}$ (Supplemental Figure 2).

HCV infection in mice with high human chimerism. We inoculated 5 highly repopulated chimeric mice with $2 \times 10^{4}$ focus-forming units (ffu) of HCV genotype 2a (JFH-1 strain). HCV RNA could be detected 24 hours later and increased after 1 week in inoculated chimeric mice (Figure 3A). Interestingly, there was no further increase in titer thereafter. Six weeks after inoculation, we harvested the livers and analyzed them for HCV RNA. Figure 3C shows that HCV RNA could be detected in all of the examined livers.

In order to determine whether these mice were susceptible to other HCV genotypes, we inoculated 2 chimeric mice with a clinical sample of HCV genotype $1 \mathrm{a}$ and 1 mouse each with 2 different genotypes - the chimeric HCV viruses $1 \mathrm{a} / 2 \mathrm{a}$ and $1 \mathrm{~b} / 2 \mathrm{a}(\mathrm{H} 77 / \mathrm{C} 3$ and Con $1 / \mathrm{C} 3$ ) - that are infectious in vitro (18). Figure $3 \mathrm{~B}$ shows that all the different HCV genotypes could be propagated in chimeric mice. Intriguingly, there was a 1,000-fold difference in titers between the clinical sample (mouse 164 and 195) and the chimeric HCV genomes (mouse 205 and 206). The successful propagation of all 4 different $\mathrm{HCV}$ viruses could be confirmed by the detection of HCV RNA in total liver RNA (Figure 3C). Like HCV RNA levels in the serum, intrahepatic HCV RNA levels normalized for human GAPDH did not correlate with human serum albumin levels and hence repopulation rates. Liver tissue of chimeric mice was stained for HCV nonstructural protein 5A (NS5a) and FAH. Figure 3, E-G, shows that immunostaining for NS5a colocalized with human hepatocytes that were FAH positive. Histological examination did not reveal any cytopathic effect of HCV infection (data not shown). In a few chimeric livers, we observed hepatocellular carcinoma, exclusively originating from mouse tissue. Hence, these tumors reflect a known complication of tyrosinemia type I rather than virus-related tumor growth (19).

Antiviral therapy in human liver chimeric mice. To extend the utility of this animal model, we explored its suitability for evaluation of antiviral drug efficacy. The state-of-the-art therapy against HCV is the combination of pegylated interferon $\alpha 2 \mathrm{a}$ (peg-IFN) and the nucleoside analog ribavirin. We compared this therapy to a more experimental therapy in clinical evaluation (19), the cyclophilin inhibitor Debio 025. We set up 1 control group without treatment and 3 treatment groups (peg-IFN alone, peg-IFN and ribavirin, peg-IFN and Debio 025). The control group received saline injections and oral gavages of the vehicle only. All 12 animals $(4 \times 3$ mice) had high human liver chimerism and were inoculated with a clinical isolate of HCV genotype 1a. Antiviral therapy was performed for 2 weeks, after animals had reached the plateau phase of $\mathrm{HCV}$ titer (day 21). All treated animals showed an approximately $3 \log$ reduction in HCV RNA after 2 weeks of treatment (Figure $3 \mathrm{D}$ ). We also inoculated 2 mice with a clinical isolate of HCV genotype 3a, which is known to be more sensitive to interferon. Indeed viral titers decreased even further than those of HCV genotype 1a upon peg-IFN treatment (Supplemental Figure 3). All treatments were well tolerated by all animals.

We investigated yet another class of antiviral compounds, this time in human liver chimeric mice infected with HBV. The nucleo- 

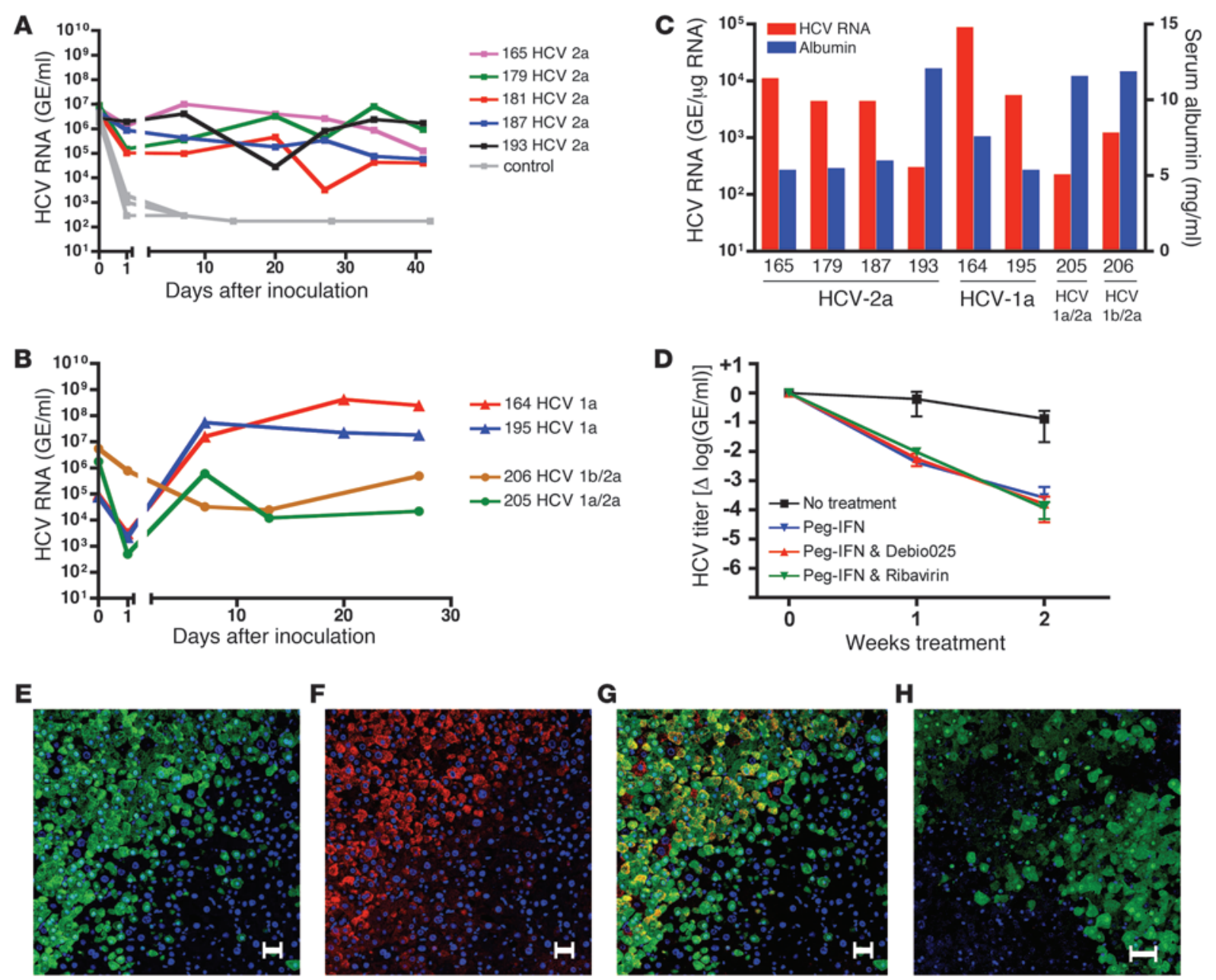

Figure 3

$\mathrm{HCV}$ infection of mice with high human chimerism. HCV RNA in mouse serum after inoculation with HCV genotype 2a (A) or clinical isolate of HCV genotype 1a or chimeric HCV genotypes (1a/2a and 1b/2a) (B). (C) HCV RNA intermediates detected in chimeric livers and human albumin levels in the murine serum of HCV-infected mice. HCV RNA was normalized to human GAPDH levels and expressed as GE per $\mu \mathrm{g}$ total RNA. (D) Antiviral treatment with peg-IFN alone, peg-IFN and ribavirin, and peg-IFN and Debio 025 for 2 weeks. Results are shown as normalized mean \pm SD. (E-G) Fluorescent costaining of an HCV-infected chimeric liver for FAH (green) and HCV NS5a (red); nuclear counterstaining with DAPI (blue). (E) FAH and nuclear staining. (F) NS5a and nuclear staining. (G) Merge of $\mathbf{E}$ and $\mathbf{F}$ showing colocalization of HCV and human hepatocytes in yellow. (H) Control mouse liver repopulated with human hepatocytes but not inoculated with HCV. Costaining for FAH (green) and HCV NS5a (red); nuclear counterstaining with DAPI (blue). Scale bars: $50 \mu \mathrm{m}$.

tide analog adefovir dipivoxil, which is used in the treatment of HBV patients, could lower the HBV titers in the murine serum (Supplemental Methods and Supplemental Figure 4).

Sustained viral propagation in human liver chimeric mice. To evaluate long-term infection, we inoculated 6 animals with HCV genotype 1 and monitored them for more than half a year ( 34 weeks). Three of the 6 mice had been treated with the peg-IFN and Debio 025 for 4 weeks. Five to 6 weeks after antiviral therapy was ceased, the mean HCV levels of the treatment group were again comparable to those of the nontreated ones and reached plateau phase for the remainder of the study (Figure 4A).

Encouraged by this long-term propagation in human liver chimeric mice, we were interested to see whether the virus could also be passaged from one chimeric mouse to another. We inoculated 2 mice with a clinical sample of HCV genotype 1a (Figure 4B). After 4 weeks, we used their serum to inoculate 2 different mice by dilut- ing the virus to match the titer of the clinical inoculum (Figure 4C). The HCV RNA levels of the 4 mice were comparable in terms of maximal viral titer and kinetics of early infection.

Some of the chimeric mice used for HBV and HCV infection were repopulated with hepatocytes from the same donor (Supplemental Tables 1 and 2) and therefore offered the possibility to compare viral infection under standardized host conditions. Supplemental Figure 5 shows HBV and HCV infection in chimeric mice of the same hepatocyte donor (44-year-old, mixed European descent) and exemplifies the differences in viral dynamics not only between $\mathrm{HBV}$ and $\mathrm{HCV}$, but also between different $\mathrm{HCV}$ isolates.

\section{Discussion}

We describe in this study the propagation of hepatotropic viruses in human liver chimeric mice. In a series of experiments using more than 60 chimeric $\mathrm{Fah}^{-/-} \mathrm{Rag}^{-/-} \mathrm{Il} 2 \mathrm{rg}^{-/}$mice, we have estab- 
A

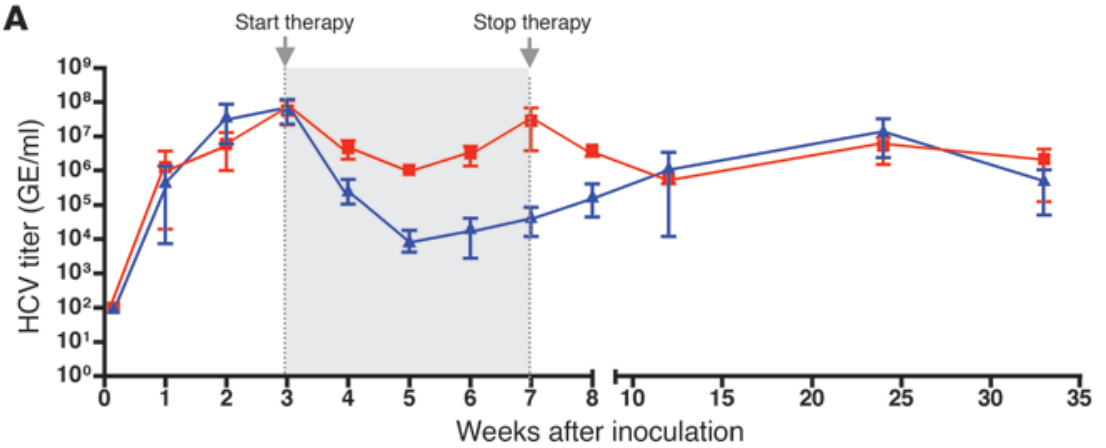

\section{Figure 4}

Long-term propagation and serial passage of HCV. (A) Mice were treated for 4 weeks with peg-IFN and Debio 025. The treatment was started 3 weeks after inoculation with HCV genotype 1a, when the viral titers reached the plateau phase. Serum HCV RNA levels are presented as mean \pm range of treatment (blue, $n=3$ ) and control (red, $n=3$ ) groups. (B) Two mice were inoculated with a clinical isolate of HCV genotype 1a. (C) Serum from mouse 164 and 195 was used as inoculum for mouse 235 and 239 (see text for details).

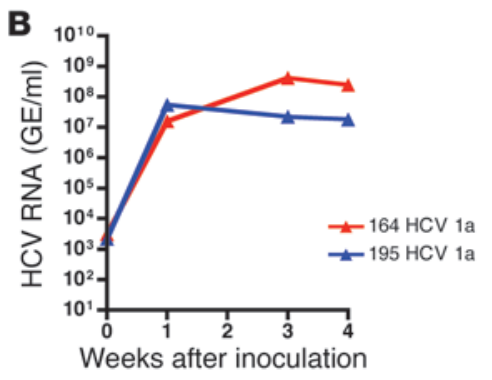

lished the conditions for successful HBV and HCV infection. In these animals, the selection pressure for transplanted human hepatocytes can be regulated by the drug NTBC, in the absence of which mouse hepatocytes die due to the accumulation of toxic tyrosine catabolites caused by the lack of FAH, while human hepatocytes stay healthy due to the human homolog. This leads to a growth disadvantage for mouse hepatocytes and positive selection for transplanted human hepatocytes. The human cells expand and can repopulate up to approximately $95 \%$ of the murine liver. The advantage of this regulatable system is that animals with low human chimerism can be put back on the drug NTBC and hence do not undergo liver failure and eventually death. Our study reveals that even minimally repopulated chimeric mice (human serum albumin, $0.04-0.16 \mathrm{mg} / \mathrm{ml}$ ) can be productively infected by $\mathrm{HBV}$, reflecting the highly infectious nature of $\mathrm{HBV}$ and/or the high rate of HBV production by each infected hepatocyte.

Mice with low human chimerism $(<10 \%)$ could not be infected with HCV (data not shown). We reasoned that high chimerism would solve that problem and therefore optimized repopulation rates. We show that a high initial hepatocyte dose $\left(3 \times 10^{6}\right.$ to $5 \times 10^{6}$ per mouse) is sufficient to reproducibly generate high human chimerism. We and others reported the transplantation of up to $1 \times 10^{6}$ human hepatocytes in the $\mathrm{Fah}^{-/-} \mathrm{Rag}^{-/-} \mathrm{Il2} \mathrm{rg}^{-1}$ mouse $(15,16)$. If the engraftment rate is linear, this low dose should expand to approximately $3 \times 10^{6}$ to $5 \times 10^{6}$ hepatocytes (i.e., the high hepatocyte transplantation dose reported herein) after only 2 cell cycles in the murine liver. However, in our hands, most of the mice transplanted with a low cell dose never reached high repopulation rates.

Mice with high human chimerism do not need to be maintained on NTBC and have a human albumin level greater than $2 \mathrm{mg} / \mathrm{ml}$, which corresponds to a human repopulation rate of greater than $10 \%$ (morphometry for FAH immunostaining). While HBV can infect livers largely independently of the extent of human chimerism, successful HCV infection can only be established in high human chimerism, which was reached 2-6 months after transplan- tation. When we inoculated highly repopulated mice with $\mathrm{HCV}$, we were able to infect with a variety of different HCV strains (Figure 3 and Supplemental Figure 3). Infection with the clinical HCV genotype $1 \mathrm{a}$ isolate yielded the highest titers (up to $10^{9} \mathrm{GE} / \mathrm{ml}$ ). This probably reflects genotype differences and not differences in the repopulation rates, since there was no correlation between serum albumin and HCV RNA levels (Figure 3C). Our study also demonstrates that intergenotypic $(1 \mathrm{a} / 2 \mathrm{a}$ and $1 \mathrm{~b} / 2 \mathrm{a})$ chimeric viruses are infectious and can propagate in vivo.

Further, we show that this animal model is suitable for candidate antiviral drug screening. We compared the state-of-the-art treatment (peg-IFN and ribavirin) for HCV with a novel combination therapy (peg-IFN and Debio 025) (20) in the clinically mostchallenging HCV genotype 1. Although no significant difference could be found among the treatment groups, our results demonstrate the feasibility and effectiveness of antiviral treatment in this chimeric mouse model. Further, we recapitulated the differences in interferon sensitivity of HCV genotype $1 \mathrm{a}$ and $3 \mathrm{a}$.

We further show that viral propagation in these chimeric animals can be sustained for more than half a year and most likely does not have any impact on the animal's health. HCV can also be passaged from one chimeric mouse to another with viral titers and dynamics similar to those achieved with inoculation with patient serum.

In summary, this study introduces a new in vivo animal model for the study of hepatotropic viruses. Further, we show that a high cell dose is sufficient for reproducibly generating mice with high human liver chimerism. The results along with the relative ease of handling the chimeric $\mathrm{Fah}^{-/-} \mathrm{Rag}^{-/-} \mathrm{Il} 2 \mathrm{rg}^{-/-}$mouse suggest that this model will greatly expand the experimental possibilities for the study of HBV and HCV infection and the evaluation of antiviral drugs.

\section{Methods}

Mice. All animal studies were reviewed and approved by the IACUC of the Salk Institute for Biological Studies. Fab ${ }^{-/-} \mathrm{Rag}^{-/-} \mathrm{Il2} \mathrm{rg}^{-/-}$mice (mixed background: C57BL/6 and 129Sv) were kept on $7.5 \mathrm{mg} / \mathrm{l} \mathrm{NTBC}(100 \%)$ in the 
drinking water and in temperature- and humidity-controlled animal quarters with a 12-hour light/12-hour dark cycle. Besides NTBC and the antiviral therapy described below, no other drugs were used during the entire study.

Transplantation of human hepatocytes. Hepatocytes were purchased from CellzDirect. Hepatocytes were shipped as cell pellets on ice in the provided medium. Upon arrival, cells were washed once with $50 \mathrm{ml} \mathrm{HBM}$ (Lonza) and kept on ice until transplantation (within 48 hours after isolation). Two- to 4-month-old mice underwent transplantation as previously described (16), except that the cell dose was increased to $3 \times 10^{6}$ to $5 \times 10^{6}$ hepatocytes per mouse. NTBC was withdrawn in a stepwise fashion: 2 successive days at $25 \%$, then $12 \%$, and then $6 \%$ of colony maintenance concentration $(7.5 \mathrm{mg} / \mathrm{l})$, prior to termination of drug therapy. After 2-6 weeks, mice with clinical symptoms (lethargy, hunched posture) or severe weight loss were put again on NTBC for 3 days before second withdrawal (cycling). Cycling was repeated until clinical symptoms resolved. Chimeric mice that were kept for long-term experiments ( $>6$ months) were subjected to further NTBC treatment in order to prevent development of hepatocellular carcinoma from mouse hepatocytes.

Inoculation with $\mathrm{HBV}$ and $\mathrm{HCV}$. Chimeric $\mathrm{Fah}^{-/-} \mathrm{Rag}^{-/-} \mathrm{Il2} \mathrm{rg}^{-/-}$mice were injected with $1 \times 10^{8} \mathrm{GE} \mathrm{HBV}$, genotype $\mathrm{D}$ (serotype ayw) into the tail vein. The inoculum was derived from the serum of an HBV-infected chimpanzee (21) and diluted in PBS to a volume of $200 \mu \mathrm{l}$.

For HCV, the following doses per mouse were used for intravenous inoculation: $100 \mu \mathrm{l} \mathrm{Huh}-7$ cell culture supernatants diluted in $100 \mu \mathrm{l} \mathrm{PBS}$ containing $2 \times 10^{4} \mathrm{ffu}$ JFH-1 (22), $3 \times 10^{3} \mathrm{ffu}$ HCV Con1/C3 (18), $3 \times 10^{3} \mathrm{ffu}$ HCV H77/ $\mathrm{C} 3$ (18) and $100 \mu \mathrm{l}$ of patient serum containing $2 \times 10^{5} \mathrm{GE} / \mathrm{ml} \mathrm{HCV}$ genotype 1 a or $2 \times 10^{5} \mathrm{IU} / \mathrm{ml} \mathrm{HCV}$ genotype 3 a diluted in PBS to a volume of $200 \mu \mathrm{l}$.

Antiviral therapy. $\mathrm{Fah}^{-/-} \mathrm{Rag}^{-/-} \mathrm{Il} 2 \mathrm{rg}^{-/-}$mice with high human chimerism were injected in the tail vein with $2 \times 10^{5} \mathrm{GE} \mathrm{HCV}$ genotype 1 a (or genotype 3a) diluted in PBS to a volume of $200 \mu \mathrm{l}$. Where indicated, animals were treated with peg-IFN (Pegasys, Roche Inc.) twice a week at $30 \mu \mathrm{g} / \mathrm{kg}$ subcutaneously alone or in combination with either Debio 025 (daily at $100 \mathrm{mg} / \mathrm{kg}$ by gavage; Debiopharm SA) or ribavirin (daily $10 \mathrm{mg} / \mathrm{kg}$ by gavage; Toronto Research Chemicals Inc.). Control animals were treated twice a week with injection of $100 \mu \mathrm{l}$ saline subcutaneously and daily gavage of the vehicle only.

Serological and blood analysis. Serum was harvested by retro-orbital bleeding and stored in aliquots for further analysis. Human albumin in the murine blood was assessed by ELISA (Bethyl Laboratories) according to the manufacturer's manual. Serum dilutions of 10 - to 10,000 -fold were used to get values within the linear range of the standard curve.

HBV DNA was extracted from $50 \mu \mathrm{l}$ serum by proteinase $\mathrm{K}$ digestion as previously described (23), and serum HBV DNA levels were analyzed by real-time quantitative PCR (QPCR) using HBV-specific primers as previously described (24).

HCV RNA was extracted from $50 \mu$ l serum by a modified guanidine thiocyanate method exactly as previously described (23), and serum HCV RNA levels were analyzed by RT-QPCR using HCV-specific primers as previously described (22).

Immunostaining. Liver tissue was harvested and either fixed in $4 \%$ paraformaldehyde for subsequent immunostaining or immediately snap-fro- zen for RNA and DNA extraction. Paraffin-embedded sections of fixed liver were dewaxed and rehydrated through xylene and decreasing concentrations of ethanol. The sections were incubated with primary antibodies (monoclonal mouse anti-FAH [1:5,000; gift from Robert M. Tanguay, Université Laval, Quebec City, Canada] or polyclonal goat anti-FAH [1:100; Santa Cruz Biotechnology Inc.]), monoclonal mouse anti-cytokeratin-18 (Dako), polyclonal rabbit anti-HBc-Ag (1:4,000; Dako) overnight or with polyclonal rabbit anti-HCV NS5a (gift of M. Houghton, Chiron, Emeryville, California) for 1 hour. Immunoreactivity was assessed either with a streptavidin-biotin amplification and diaminobenzidine or with fluorescently labeled secondary antibodies (counterstaining with DAPI) for the double staining (counterstaining with hematoxylin).

Detection of HBV and HCV intermediates in the liver. For HBV cccDNA and HBV DNA replicative intermediate analysis, frozen liver tissue was homogenized as previously described (24). Ninety percent of the homogenate was used to extract cccDNA, and the rest of the homogenate was used to extract total liver DNA as previously described (24). HBV cccDNA and replicative intermediates were analyzed by real-time QPCR using HBV-specific primers as previously described (24). The percentage of human DNA was determined by QPCR for the mouse and human GIMAP1 gene as previously described (25), and HBV DNA copy numbers per nanogram of total liver DNA were normalized for the percentage of human IMAP. For intrahepatic RNA analysis, total liver RNA was isolated by a modified guanidine thiocyanate method exactly as previously described (26). HBV, HCV, and human and mouse GAPDH RNA was quantified in $1 \mu \mathrm{g}$ total RNA by realtime RT-PCR using virus- and gene-specific primers as previously described (22), and HCV and HBV RNA copy numbers per nanogram of total liver RNA were normalized for the percentage of human GAPDH.

Statistics. Data are shown as mean $\pm \mathrm{SD}$ or mean \pm range. The statistical differences of results were analyzed by Kruskal-Wallis test using the GraphPad Prism program. $P$ values of 0.05 or less were considered significant.

\section{Acknowledgments}

The authors thank Joe Chambers, Jacob Lopez, and Christina Whitten for technical assistance; Konrad Streetz for valuable discussions; and Gerald Pao for critical reading of the manuscript. This work was supported by grants to I.M. Verma from the American Cancer Society, the NIH (NHLBI HL53670), the Leducq Foundation, the Ellison Medical Foundation, Ipsen Biomeasure, Sanofi-Aventis, and the H.N. and Frances C. Berger Foundation; and grants to F.V. Chisari from the NIH (R01-AI20001 and R01-CA40489). The content is solely the responsibility of the authors and does not necessarily represent the official views of the NHLBI or the NIH.

Received for publication June 5, 2009, and accepted in revised form December 9, 2009.

Address correspondence to: Inder M. Verma, Salk Institute for Biological Studies, Laboratory of Genetics, 10010 North Torrey Pines Road, La Jolla, CA 92037, USA. Phone: 858.453.4100 ext. 1462; Fax: 858.558.7454; E-mail: verma@salk.edu.
1. Seeger C, Mason WS. Hepatitis B virus biology. Microbiol Mol Biol Rev. 2000;64(1):51-68.

2. Wieland SF, Chisari FV. Stealth and cunning: hepatitis B and hepatitis C viruses. J Virol. 2005; 79(15):9369-9380.

3. Dienstag JL. Hepatitis B virus infection. N Engl J Med. 2008;359(14):1486-1500.

4. Llovet JM, Burroughs A, Bruix J. Hepatocellular carcinoma. Lancet. 2003;362(9399):1907-1917.

5. Barker LF, et al. Transmission of type B viral hepatitis to chimpanzees. J Infect Dis. 1973;127(6):648-662. 6. Guidotti LG, Rochford R, Chung J, Shapiro M, Purcell R, Chisari FV. Viral clearance without destruction of infected cells during acute HBV infection. Science. 1999;284(5415):825-829.

7. Abe K, Inchauspe G, Shikata T, Prince AM. Three different patterns of hepatitis $C$ virus infection in chimpanzees. Hepatology. 1992;15(4):690-695.

8. Mason WS, Seal G, Summers J. Virus of Pekin ducks with structural and biological relatedness to human hepatitis B virus. JVirol. 1980;36(3):829-836.

9. Summers J, Smolec JM, Snyder R. A virus similar to human hepatitis B virus associated with hepatitis and hepatoma in woodchucks. Proc Natl Acad Sci US A. 1978;75(9):4533-4537.

10. Marion PL, Oshiro LS, Regnery DC, Scullard GH, Robinson WS. A virus in Beechey ground squirrels that is related to hepatitis B virus of humans. Proc Natl Acad Sci U S A. 1980;77(5):2941-2945.

11. Yang PL, Althage A, Chung J, Chisari FV. Hydro- 
dynamic injection of viral DNA: a mouse model of acute hepatitis B virus infection. Proc Natl Acad Sci US A. 2002;99(21):13825-13830.

12. Heckel JL, Sandgren EP, Degen JL, Palmiter RD, Brinster RL. Neonatal bleeding in transgenic mice expressing urokinase-type plasminogen activator. Cell. 1990;62(3):447-456.

13. Dandri M, et al. Repopulation of mouse liver with human hepatocytes and in vivo infection with hepatitis B virus. Hepatology. 2001;33(4):981-988.

14. Mercer DF, et al. Hepatitis C virus replication in mice with chimeric human livers. Nat Med. 2001; 7(8):927-933.

15. Azuma H, et al. Robust expansion of human hepatocytes in Fah $\left({ }^{-/}\right) / \operatorname{Rag} 2\left(^{(-/}\right) / \operatorname{Il} 2 \mathrm{rg}\left(^{-/-}\right)$mice. Nat Biotechnol. 2007;25(8):903-910.

16. Bissig KD, Le TT, Woods NB, Verma IM. Repopulation of adult and neonatal mice with human hepatocytes: a chimeric animal model. Proc Natl
Acad Sci U S A. 2007;104(51):20507-20511.

17. Grompe M, et al. Loss of fumarylacetoacetate hydrolase is responsible for the neonatal hepatic dysfunction phenotype of lethal albino mice. Genes Dev. 1993;7(12A):2298-2307.

18. Pietschmann T, et al. Construction and characterization of infectious intragenotypic and intergenotypic hepatitis C virus chimeras. Proc Natl Acad Sci US A. 2006;103(19):7408-7413.

19. Goldsmith LA, Laberge C. 1989. Tyrosinemia and related disorders. In: Scriver CR, Beaudet AL, Sly AS, Valle D, eds. The Metabolic Basis of Inherited Disease. New York: McGraw-Hill. 547-562.

20. Flisiak R, et al. The cyclophilin inhibitor Debio 025 combined with PEG IFNalpha2a significantly reduces viral load in treatment-naive hepatitis $C$ patients. Hepatology. 2009;49(5):1460-1468.

21. Murray JM, Wieland SF, Purcell RH, Chisari FV. Dynamics of hepatitis B virus clearance in chimpanzees. Proc Natl Acad Sci U S A. 2005; 102(49):17780-17785.

22. Zhong $\mathrm{J}$, et al. Robust hepatitis $\mathrm{C}$ virus infection in vitro. Proc Natl Acad Sci U S A. 2005; 102(26):9294-9299.

23. Wieland SF, Guidotti LG, Chisari FV. Intrahepatic induction of alpha/beta interferon eliminates viral RNA-containing capsids in hepatitis B virus transgenic mice. J Virol. 2000;74(9):4165-4173.

24. Wieland SF, Spangenberg HC, Thimme R, Purcell RH, Chisari FV. Expansion and contraction of the hepatitis $B$ virus transcriptional template in infected chimpanzees. Proc Natl Acad Sci U S A. 2004;101(7):2129-2134.

25. Meuleman $P$, et al. Immune suppression uncovers endogenous cytopathic effects of the hepatitis B virus. J Virol. 2006;80(6):2797-2807.

26. Guidotti LG, Matzke B, Schaller H, Chisari FV. High-level hepatitis B virus replication in transgenic mice. J Virol. 1995;69(10):6158-6169. 